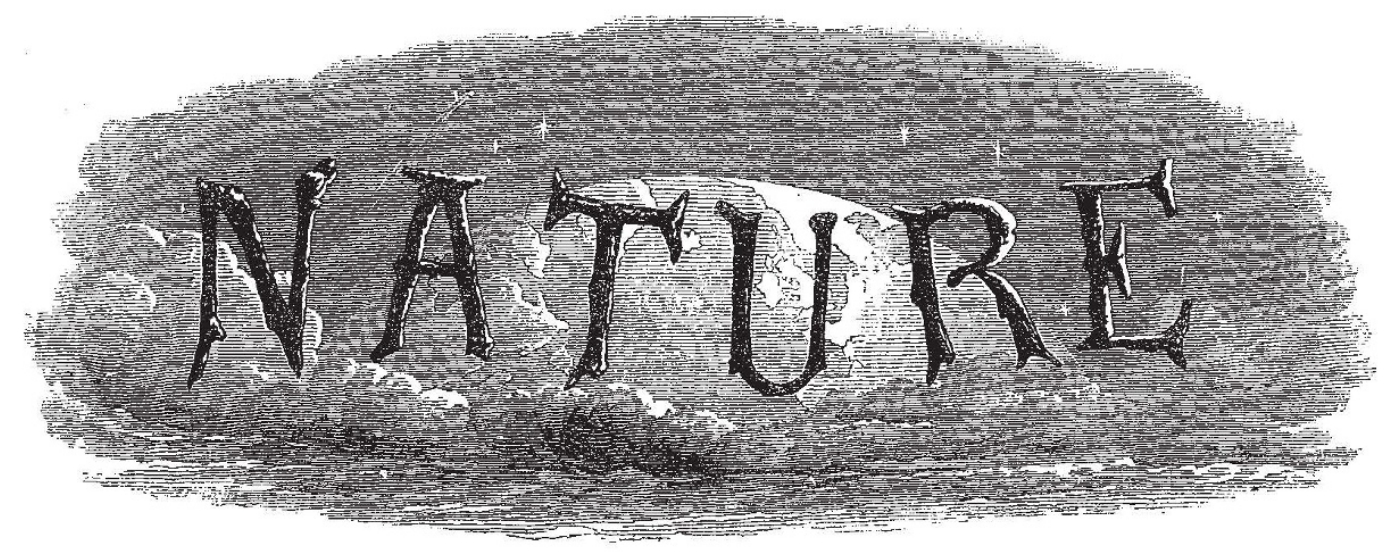

A WEEKLY ILLUSTRATED JOURNAL OF SCIENCE

"To the solid grouna

of Nature trusts the mind which builds for aye."-WORDSWORTH

THURSDAY, NOVEMBER $\mathrm{I}, \mathrm{I} 877$

\section{THE SUN'S DISTANCE}

$\mathrm{A}$ MOST interesting state paper has just been issued ; we refer to the Report by the Astronomer-Royal on the Telescopic Observations of the Transit of Venus of 1874 , made by the Expeditions sent out by the British Government and the results deduced from them. The Astronomer-Royal suggests that another report may be called for when the photographs of the transit have been completely measured and worked out, if possible in combination with the results of similar observations made in the expeditions organised by other governments.

It will be seen from the present Report that the plan of operations actually pursued has been very nearly that proposed by the Astronomer-Royal in his communication to the Royal Astronomical Society on December I I, I868, when for the third time directing attention to the arrangements which it would be necessary to make for the efficient observation of the transits of 1874 and 1882 . The method of absolute longitudes was to be applied for observations both of ingress and egress; it being therefore essential that the longitudes of the observing-stations should be determined with precision; and the longitudes recommended to be fixed by Great Britain were Alexandria, stations in New Zealand and in the Sandwich Islands, Kerguelen's Land, and Mauritius or the two islands of Rodriguez and Bourbon.

The stations eventually selected for observations by the British expedition were fixed upon "entirely by consideration of the influence which their positions would have in determining with accuracy the necessary alteration of parallax." They were : Egypt, the Sandwich Islands, the Island of Rodriguez, New Zealand, and Kerguelen's Land, It was intended to adopt in each of these districts one fundamental station, the longitude of which was to be independently determined, for conversion of local times into Greenwich times, and subordinate to this primary station, other stations were proposed to be selected at such distances that advantage might be taken of different states of weather that might possibly prevail.

In Egypt his Highness the Khedive rendered every Vol. XVII, - NO. 418 possible assistance, tents being supplied with military guards for the protection of the observers and their instruments, and telegraph wires erected. The AstronomerRoyal acknowledges the obligations of the expedition to the liberality of the Eastern Telegraph Company, in affording the means of determining with extreme accuracy and great facility the longitude of the principal station Mokattam. Greenwich was easily connected with Porth Curno, in Cornwall, whence there is an uninterrupted line to Alexandria, the longest submarine line in the world ; Alexandria was connected with Mokattam by aid of the special line constructed by the Khedive from Cairo to the station. It is further stated that timecommunication was also made from Mokattam through Cairo to Thebes, and to Suez by the ordinary telegraph, Thebes and Suez being the other Egyptian stations where the transit was observed.

In the Sandwich Islands much assistance was received from King Kalakaua and members of the reigning family. The principal station was at Honolulu, the longitude of which was determined partly by meridian-transits of the moon and partly by transits of the moon observed with the Altazimuth instrument. Waimea, in the island Kauai, where observers were also placed, was connected with Honolulu by means of chronometers carried in H.M.S. Tercdos. At the Island of Rodriguez the longitudes were determined in the same manner as for the Sandwich Islands stations, for three positions, viz., Point Venus, the Hermitage, and Point Coton; and communication was further made with the Mauritius and with Lord Lindsay's expedition with the aid of H.M.S Shearwater, the preliminary results being stated by Sir George Airy to agree closely with those given by the lunar observations. At Kerguelen's Land, again, the operations were similar; Supply Bay and Thumb Peak being the stations chosen.

In New Zealand unfavourable weather much interfered with the observations, and Sir George Airy had at first been led to suppose that all useful observation had been lost; it subsequently appeared, however, that this was not the case, one phase of the transit being well seen at Burnham, the longitude of which was fixed by meridian transits of the moon.

The Report is divided into three sections or tables. 
In the first are given the descriptions of the various phenomena, in the words of the observers, with the Green. wich sidereal times of the different phases, obtained from accurate reduction of the observations for longitude here particularised; where such longitudes depend upon lunar observations the places of the Nautical Almanac were carefully corrected by observations on nearly the same days at Greenwich, Paris, Strasburg, and Königsberg. In studying these original descriptions, Sir George Airy was led to infer that it was "possible to fix upon three distinct phases for the Ingress and four for the Egress," though it might have been supposed that Egress and Ingress would exhibit the same number of distinct phases in inverse order ; this was not the case in practice. The first phase, $a$, utilised in the calculations is the appearance of the planet just within the sun's disc, but the light between the two limbs being very obscure. After an interval of about twerty seconds "the light begins to clear, and the observers generally think that the contact is passed;" this is phase $\beta$. About twenty seconds later, the light which at phase $\beta$ was not equal to that of the suin's $\operatorname{limb}$, is free from all shadow, and the phase is called $\gamma$. Sir George Airy finds that of these phases $\beta$ is the most exact, observers, even in the presence of clouds of moderate density, agreeing within three or four seconds, though for other phases much greater discord. ances are exhibited. Similarly at the Egress, the first appearance of a fine line or faint shadow is called $\delta$, this becoming definite, or a "brown haze" appearing, is called $\epsilon$. When most observers record "contact," the shadow having reached a maximum intensity, the phase is called $\zeta$, and in this phase there is an agreement amongst observers, much closer than in other phases at Egress. The "circular" contact at Egress is called $\eta$.

In the second section of the Report, or Table II., these "adopted phases are massed for each district in which the parallax-factor is nearly identical," and several of the details of reduction are included. With the longitudes cetermined as above, the recorded times of the various phases of the transit were converted into Greenwich sidereal times. With the calculated apparent places of the sun and Venus in the Nautical Almanac, as deduced from Leverrier's Tables, an ephemeris was prepared exhibiting the predicted geocentric places for every tenth second of Greenwich sidereal time throughout the transit, and from these numbers the apparent positions of sun and planet at each station were computed. Calculations were further made, showing how the predicted places would be affected by alteration of the local longitude, by change in the tabular places of the sun and Venus, and by alteration of their tabular parallaxes; the first two alterations were not essential in these reductions, but the determination of alterations of the third class, as it is remarked, constituted "the special object of the expedition." The form of the reductions was" "entirely determined by the consideration that such alterations must be made in the parallaxes as will render the observations of the same phenomena in different parts of the earth consistent with each other." In Table III. we have "the mean solar parallax deduced from every available combination." Thus Ingress accelerated at the Sandwich Islands is compared with Ingress retarded at Rodriguez and with Ingress retarded at Kerguelen's Land; Egress retarded at Mokattam and Suez with Egress retarded at Rodriguez, and likewise with Egress accelerated at the two stations in Kerguelen's; and again the retarded Egress at Thebes is compared with Egress retarded at Rodriguez and with Egress accelerated at Kerguelen's. The greatest separate value of the solar parallax resulting from these different comparisons is 8".933 and the least $8 " 407$. Weights are given to the various determinations depending, firstly, upon the number of observations and the magnitude of the parallax-factor; and secondly, upon the particular phase $\alpha, \beta, \gamma, \delta, \epsilon$, and $\zeta$ being included. Thus it is found that all the combinations for Ingress give the mean solar parallax $8^{\prime \prime} .739$, weight 10 46, and all the combinations for Egress give 8".847, weight 2.53 , whence the general result is 8.760 , from which Sir George Airy finds the mean distance of the sun equal to $93,300,000$ miles. The New Zealand observations were not included in these calculations ; their mean result is 8.764 , almost identical with the above. It is remarked that many persons may perhaps consider that the more closely-agreeing phases $\beta$ and $\zeta$ should be employed in deducing the value of the parallax to the exclusion of the others. If this be done we shall have from the Ingress $8^{\prime \prime} \cdot 748$, and from the Egress 8".905, or with their due weights a mean value $8^{\prime \prime} \cdot 773$.

In this outline of the details contained in the Astronomer-Royal's first Report upon the observations of the transit of Venus, and the conclusions to be drawn from. them we have adhered closely to his own words. Pending the appearance of the deductions to be made from the complete measuring of the photographs, the results before us are perhaps to be regarded as provisional ones only, or we have not yet learned all that may be done from the work of the British expeditions, so laboriously organised by Sir George Airy. Many astronomers we can imagine will regard with some suspicion so small a parallax as $8^{\prime \prime} \cdot 76$, which is a tenth of a second less than has been given by the most reliable previous investigations, upon different principles. In illustration we may quote the separate results from which Prof. Newcomb obtained his value of the parallax, now adopted in most of our ephemerides :-

From meridian observations of Mars, $1862 \quad \ldots \quad \ldots \quad 8.855$

From micrometric observations of Mars, $1862 \quad \ldots .68 .842$

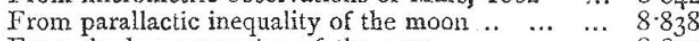

From the lunar equation of the earth $\quad \ldots \quad$...

From the transit of Venus, 1769 (Powalky's reduc-

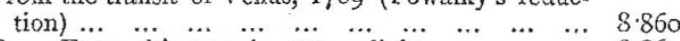

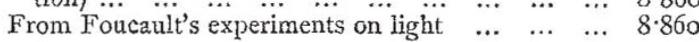

To these may be added Leverrier's value subsequently deduced from the planetary theories, which is also $8^{\prime \prime} .86$. Newcomb's mean figure, taking account of weights corresponding to the probable errors is $8 / .848$, which, with Capt. Clarke's measure of the earth's equator, implies that the mean distance of the sun is $92,393,000$ miles. Sir George Airy's $8^{\prime \prime} 760$ would similarly place the sun at a mean distance of 93,32 1,000 miles.

It is well known that some astronomers have not expected our knowledge of the sun's distance to be greatly improved from the observations of the transit of Venus, regarding such an opportunity as is presented by a close opposition of Mars as affording at least as tavourable conditions, fand the result of Mr. Gill's expedition to 
Ascension to utilise the late opposition will be on this account awaited with much interest. Nevertheless, whatever degree of opinion might be entertained by competent authorities, it appears to have been felt by those immediately responsible for action, in different civilised nations where science is encouraged, that so rare a phenomenon as a transit of Venus could not be allowed to pass without every exertion being made to utilise it, and this country may lay claim to an honourable share in the great scientific effort, thanks mainly to the long-continued and admirably-directed endeavours of the Astronomer-Royal to secure this result.

Several of the stations occupied during the transit of I 874 will be available for the transit of 1882 , Kerguelen's Land in particular, where at Ingress the sun will be at an elevation of $12^{\circ}$, the factor of parallax being $0^{\circ} 98$. In that year there will also be the advantage of observations along the whole Atlantic sea-board of the United States and Canada, where, as pointed out by the AstronomerRoyal in 1868 , the lowest factor is $0^{\circ} 95$, and the smallest altitude of the sun $12^{\circ}$ for observing the retarded Ingress; and for observing the Egress as accelerated by parallax, the factors are about 0.85 , the sun's elevation varying from $4^{\circ}$ at Halifax, to $32^{\circ}$ at New Orleans, or Jamaica. Australian and New Zealand stations are important for retarded Egress.

As is well known, the transit of Venus on December 6 , I882, will be partly visible in this country.

\section{PARKER AND EETTANY'S "MORPHOLOGY OF THE SKULL"}

The Morphology of the Skull. By W. K. Parker, F.R.S., and G. T. Bettany, M.A. (London: Macmillan and Co., 1877 .)

$\mathrm{N}$ the minds of most of those who have paid no special 1 attention to the subject the skull is regarded as a bony case formed to contain the brain, together with the face. There is also a constancy in the number and position of these bones which lead to the apparently necessary conclusion that occipital, sphenoid, parietal, and other elements are fundamental cranial structures; so that an exhaustive study of their relationships and variations might be thought entirely to cover the subject of skull structure.

That such is not the case has dawned upon us since the elaborate researches of Rathke and other able embryologists, among the foremost of whom must be placed Profs. Huxley and Gegenbauer, who have been followed by $\mathrm{Mr}$. Parker, the author of the work under consideration, who on account of his peculiar aptitude for manipulation, his untiring zeal and his immense experience, has placed the subject of cranial morphology upon a footing infinitely more satisfactory than it has previously been. His numerous memoirs in the Transactions of the Royal, Zoological, and Linnean Societies form a mine of biological facts, so beautifully supplemented by their accompanying illustrations, The perusal of them all, in their proper sequence, is however a task only to be undertaken by the specialist, and it is on this account that we have no small degree of pleasure in being able to give a notice of "The Morphology of the Skull," a work of less than four hundred pages, in which is collected, condensed, and digested the mass of information spread through the larger memoirs.

The work consists of a series of chapters on the skulls of carefully-selected types of the five classes of the Vertebrata. Those chosen are :-
I. The Dog-fish and Skate
2. The Salmon.
3. The Axolotl.
4. The Frog.
5. The Common Snake.
6. The Fowl.
7. The Pig.

These are each described in all stages from their earliest appearance in the blastoderm to their adult condition. Following each chapter is a brief résumé of the peculiarities which have been observed in other members of each group, in such a manner that the student of any particular form can learn almost all he may require with reference to any special member of the sub-kingdom.

The primitive trabeculæ cranii, together with the parachordal cartilages and the branchial arches are traced from their earliest development until ossification in and around them has reached the limits of the different types. The insufficiency of our data for the determination of the cranial segments is prominently brought forward, although the moniliform constrictions of the anterior extremity of the notochord in the fowl and in the urodeles is stated, and thought to suggest a segmentation. On the subject of the vertebral theory of the bony skull, Mr. Parker telis us that "only one bony segment, the occipital, can be said to be clearly manifest in the skulls of fishes and amphibians. And in these forms there are no good grounds for assigning to the cranial bones special names indicating a correspondence to particular parts of vertebræ. From the study of adult structures in the mammalian groups skull-theories have been devised, lacking the basis of embryology; and granting that they express some of the truth respecting the highest forms of skull, there is only injury to knowledge in arbitrarily interpreting the lower forms by them. In reptiles the skull becomes much more perfect, but with wide variations in the different groups, such that they cannot be merely subordinated to and explained by the mammalian type. A careful study of the growth of the bird's skull, again, will show that it is impossible to express its composition on a simple formula derived from vertebral structures. But from the lower to the higher forms of vertebrates we can discern a growing away from the primordial type of skull towards and into a loftier development." This result of the extensive investigation upon which it is based is somewhat paradoxical. The "loftier development" of the highest types results in a skull some of whose components may be compared in detail with some expression of truth to vertebræ, whilst in the lower forms a similar comparison cannot be said to hold. And yet true vertebræ themselves, fully developed as far as their essential details are concerned, are found in forms far from high in the scale.

Mr. Parker's invaluable investigations besides their importance in a comparative anatomical point of view, have done much to demonstrate the degree of stress which must be laid on facts of cranial structure in problems relating to classification. His labours have led him to elaborate the instructive classification of birds 